Int. J. Curr. Res. Med. Sci. (2017). 3(10): 107-111

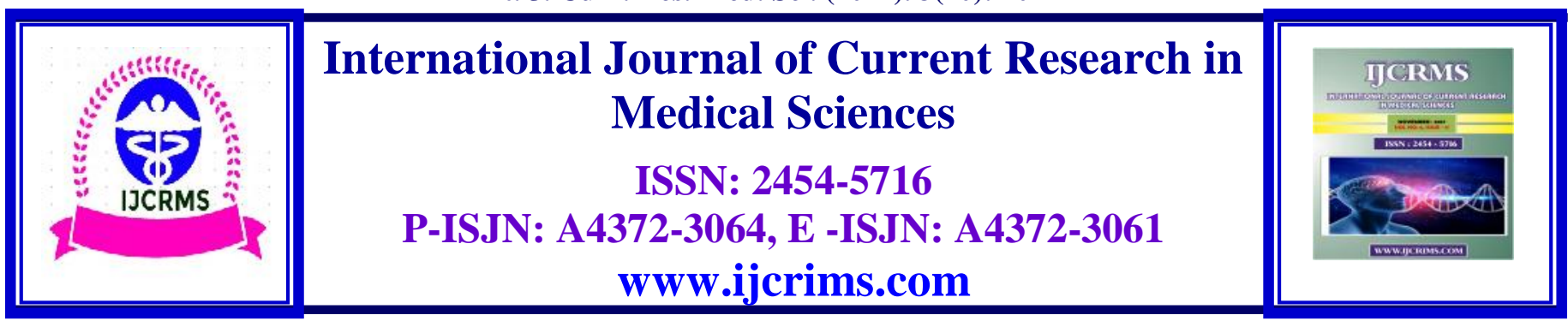

Case Report

Volume 3, Issue 10 -2017

DOI: http://dx.doi.org/10.22192/ijcrms.2017.03.10.015

\title{
ANCA Associated vasculitis presenting as bilateral pleural effusion: A rare case report
}

\author{
*Gurpreet Singh,** Rajwinder Kaur, ***NC Kajal,****Bakshish Singh \\ ****** L Avasthi, *******N.S. Neki \\ *Senior Consultant, Pulmonary Medicine \& Critical care, Satguru Partap Singh Hospital, Ludhiana, India \\ ${ }^{* *}$ Senior Resident, Satguru Partap Singh Hospital, Ludhiana, India \\ **** Professor, Chest and TB Department, Govt Medical College, Amritsar, India \\ *** Senior Consultant, Nephrology, Satguru Partap Singh Hospital, Ludhiana, India \\ Senior Consultant, Director Medical Services, Satguru Partap Singh Hospital, Ludhiana, India \\ ******Prof \& Head Medicine Dept., Govt. Medical College Amritsar, India \\ *Corresponding author: Dr Gurpreet Singh \\ E-mail: singhgurpreetdr@gmail.com
}

\section{Abstract}

ANCA associated vasculitis is frequently a multi-system disease with a predilection for affecting the respiratory tract and renal parenchyma. We report a rare case of ANCA associated vasculitis presenting as bilateral eosinophilic exudative pleural effusion. We highlight the approach to diagnose and appropriate management in such a patient.

Keywords: ANCA- Anti-neutrophilic cytoplasmic antibodies, MPO-Myeloperoxidase, Glomerulonephritis, Vasculitis.

\section{Introduction}

Vasculitis means inflammation of the blood vessel wall. Any type of blood vessel in any organ could be affected. ANCA Associated Vasculitis (AAV) is a form of vasculitis that primarily affects the small blood vessels in your body. Inflammation causes thickening of vessel wall leading to narrowing of lumen resulting in ischemia. Anti-neutrophil cytoplasmic antibody (ANCA)-associated vasculitidesare life threatening autoimmune diseases characterised by necrotising inflammation of small to mediumsized vessels. ${ }^{1-3}$
Three systemic autoimmune small vessel vasculitis syndromes are associated with antineutrophil cytoplasmic autoantibodies (ANCAs); collectively, they're called ANCAassociated vasculitis (AAV). AAV include (1) Microscopic polyangiitis (MPA) Granulomatosis with polyangiitis (GPA), formerly known as Wegener's granulomatosis\& (3) Eosinophilic granulomatosis with polyangiitis (EGPA), formerly known as Churg-Strauss syndrome. AAV is frequently a multi-system disease with a predilection for affecting the 
respiratory tract and renalparenchyma. ${ }^{2}$ When the kidneys are involved, AAV typically gives rise to rapidly progressive renal failure and necrotising crescentic glomerulonephritis. ${ }^{5}$ In contrast to immune-complex associated diseases (i.e., systemic lupus erythematosus or IgA vasculitis), the hallmark of AAV is the lack or paucity of immunoglobulin and complement deposits. ${ }^{4,6}$

\section{Case Report}

A 70 yrs male presented with complaints of fever, loss of appetite for 2 months and breathlessness for 1 month. 6 years back, patient had history of coronary artery disease for which percutaneous trans-luminal coronary angioplasty was done. Patient was evaluated at private hospital and found to have bilateral eosinophilic exudative pleural effusion and was empirically put on antituberculosis treatment.

On general physical examination, patient was febrile and tachypneic. On respiratory system examination patient had fine crepitations. Examination findings of other systems were within normal limits. Chest X-Ray showed patchy radio-opacities in bilateral lower zones with obscured right costophrenic angle. CT chest showed multiple fibro- atelectatic bands with few areas of tractional bronchiectasis right middle and bilateral lower lobes and inferior lingular segment of left upper lobe, with patchy areas of GGO right upper lobe with bilateral mild pleural effusion. Abdomen USG revealed mild hepatomegaly.

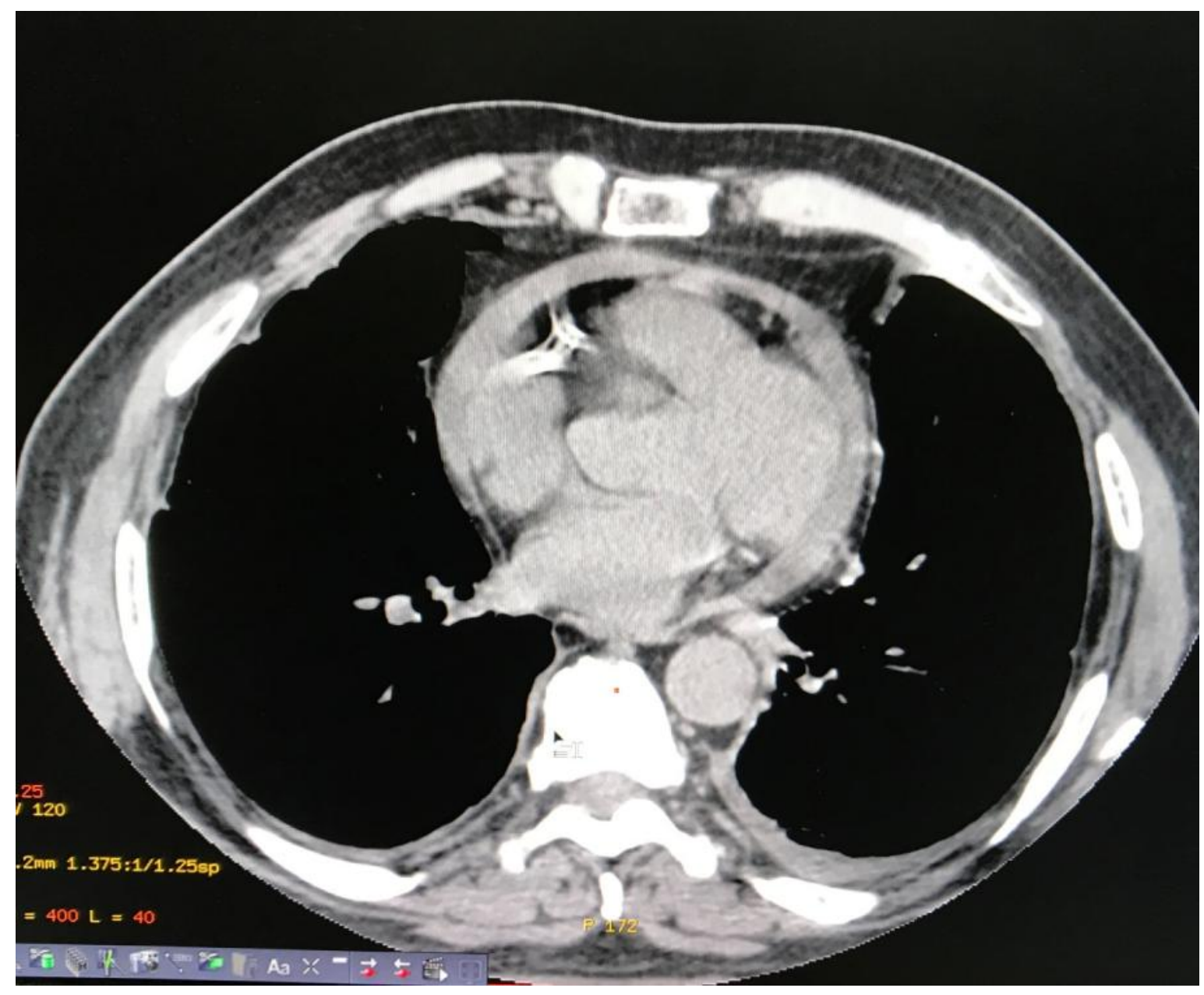

Figure 1. CT chest showing mild pleural effusion with pericardial effusion. 
2D echo was done which showed mild pericardial effusion. In view of hoarseness of voice, ENT consultation was taken and CT of PNS was done which showed mild deviated nasal septum towards right. Hemogram showed normal profile. Liver and renal function tests were within normal limits. The coagulation profile and electrolytes were also unremarkable. The erythrocyte sedimentation rate (ESR) was $64 \mathrm{~mm} /$ hour. Absolute eosinophil count was $475 / \mathrm{CU}$. Urine examination showed protein+++, urinary protein (24hrs) showed high protein loss $(839 \mathrm{mg} / 24$ hrs). Vasculitic profile was done which came out to be positive for antibodies against MPO \& cANCA was positive. Due to elevated titre of cANCA and presence of anti-MPO antibodies, USG guided renal biopsy was done. Report came out to be focal segmental necrotizing glomerulonephritis with 20-30\% crescents. Pulse therapy with I/v Methyl prednisolone 1 gm daily for 3 days given, subsequently prednisolone 60 $\mathrm{mg}$ along with cyclophosphamide $200 \mathrm{mg}$.

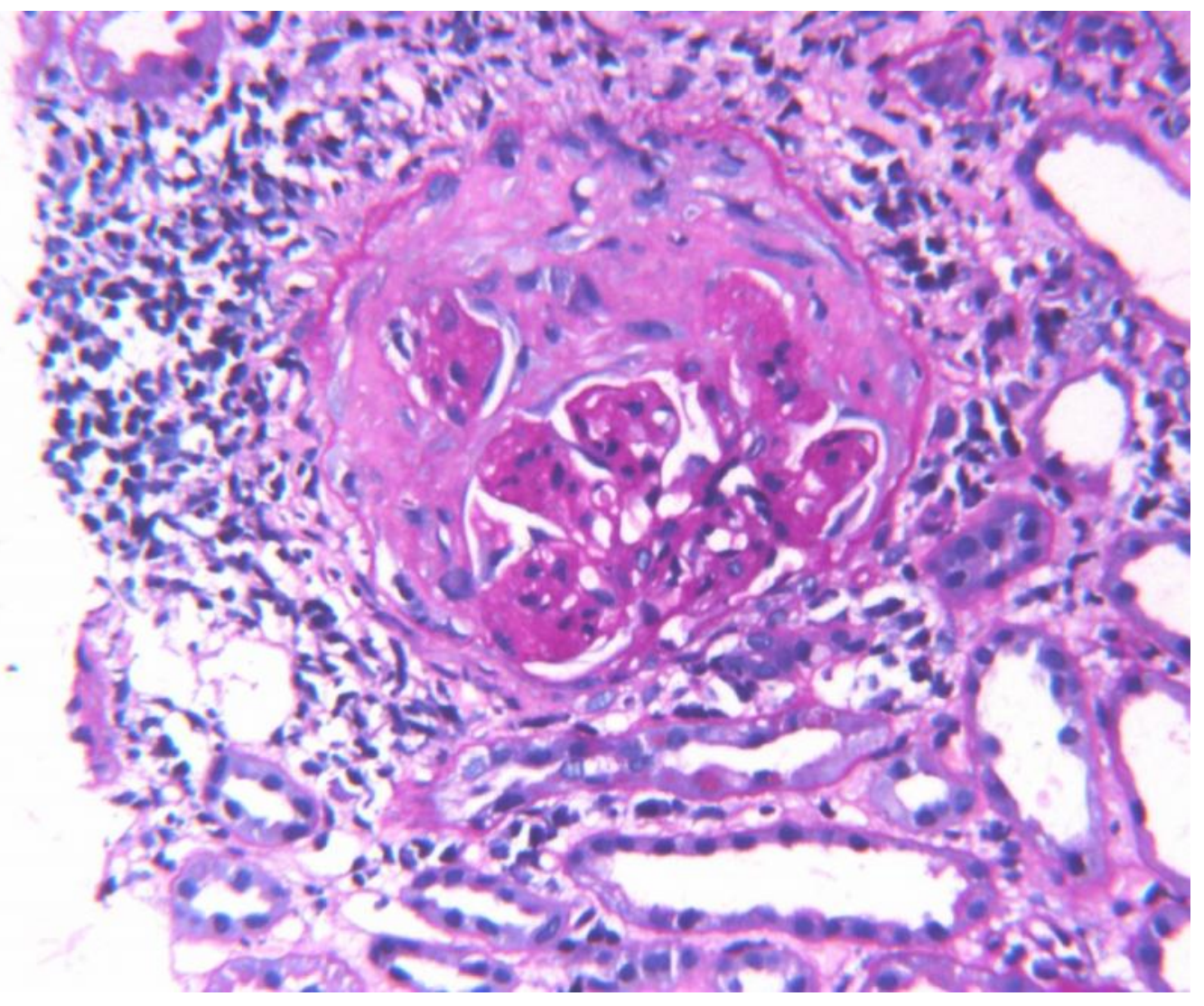

Figure 2 Renal biopsy showing focal segmental necrotizing glomerulonephritis withcrescents.

\section{Discussion}

ANCAs are antibodies against intracellular Antigens which are found in neutrophils and monocytes. The ANCA-associated vasculitisare grouped together because they share common clinical, histopathologic features and similar response to immunosuppressive treatment. ${ }^{7}$

Constitutional symptoms are also common. ${ }^{6,7,8}$ Renal involvement in vasculitis may progress to renal failure and renal biopsy commonly reveals glomerulonephritis. Although renal-limited vasculitis is closely associated with ANCAs, WG, microscopic polyangiitis (MPA) and Churg-Strauss syndrome are systemic forms of ANCA-associated vasculitis (AAV) with common extra-renal involvement. Thoracic involvement is most commonly seen with primary idiopathic large-vessel vasculitides (Takayasu arteritis, giant cell arteritis, Behçet disease)and primary small vessel ANCA-associated vasculitides . 
The lung is the most commonly involved organ in EGPA, followed by the skin. Pulmonary hemorrhage and glomerulonephritis are much less common than in the other small vessel vasculitides. ${ }^{10}$ Renal involvement is infrequent; the characteristic lesion is a focal segmental glomerulonephritis. ${ }^{1,7}$ Eosinophilic pleural effusion represents $5-8 \%$ of all exudative pleural effusions seen . EPE alsopresents the early (prevasculitic) phase of the EGPA. Most common presentation of GPA being lung nodules (40-70\% of patients) usually multiple and bilateral and occur without a zonal predilection. Cavitation occurs in approximately $25 \%$ of nodules larger than $2 \mathrm{~cm} .{ }^{11}$ Parenchymal consolidation and pleural involvement are less frequent in GPA. Pleural lesions are present in only $10 \%$ of GPA patients with initial pulmonary involvement. ${ }^{12} \mathrm{As}$ seen in our case report, a rare presentation of bilateral eosinopleural fluid was also reported in a study conducted by Krenke et al. ${ }^{13}$

Induction of remission should be done with cyclophosphamide. alternative agents are methotrexate and mycophenolatemofetil. In case of creatinine $>500 \mathrm{micromol} / \mathrm{l} \mathrm{GC}$ and plasma exchange should be considered.Rituximab in combination with glucocorticoids is also used in both remission and maintainancephase. High risk of relapse is there in therapy of $<1 \mathrm{yr}$. so duration of treatment should be atleast 18-24 months.

\section{Conclusion}

Eosinophilic pleural effusion is not common phenomenon but ANCA-associated small-vessel vasculitis should be suspected in any patient presenting with eosinophilic pleural effusion and multi-system involvement once infectious or malignant causes are ruled out. Therefore, possibilities of ANCA associated Vasculitis should be kept in mind while treating patients having exudative pleural effusion with eosinophilia.

\section{Source of funding: Nil}

Conflict of interest: None declared

\section{References}

1.Jennette JC, Falk RJ, Hu P, Xiao H. Pathogenesis of antineutrophil cytoplasmic autoantibody-associated small - vessel vasculitis. Annual review of pathology. 2013; 8:139-60.doi:10.1146/annurev-pathol-011811132453 PMID: 23347350.

2. Jennette JC, Falk RJ.Small-vessel vasculitis. N Engl J Med. 1997; 337(21):1512-23. PMID: 9366584.

3. Beauvillain C, Delneste Y, Renier G, Jeannin P, Subra JF, Chevailler A. Antineutrophil cytoplasmic autoantibodies: how should the biologist manage them? Clin Rev Allergy Immunol. 2008; 35(1-2):47-58. doi: 10.1007/s12016-007-8071-9 PMID: 18176846.

4. Jennette JC, Falk RJ, Bacon PA, Basu N, Cid MC, Ferrario F, et al. 2012 revised International Chapel Hill Consensus Conference Nomenclature of Vasculitides. Arthritis Rheum. 2013; 65(1):1-11. doi: 10.1002/art.37715 PMID: 23045170.

5. Sinico RA, Di Toma L, Radice A. Renal involvement in anti-neutrophil cytoplasmic autoantibody associated vasculitis. Autoimmun Rev. 2013; 12(4):477-82. doi: 10.1016/j.autrev.2012.08.006 PMID:22921791.

6. Henique C, Papista C, Guyonnet L, Lenoir O, Tharaux PL. Update on crescenticglomerulonephritis.SeminImmunopa thol. 2014; 36(4):479-90. doi: 10.1007/s00281-014-0435-7 PMID: 24948005.

7. E. Casta ner, A. Alguersuari, X. Gallardo et al., "When to suspectPulmonaryvasculitis: radiologic and clinical clues," Radiographics, vol. 30, no. 1, pp. 33-53, 2010.

8. Fauci AS, Haynes B. Katz P. The spectrum of vasculitis: clinical, pathologic, immunologic and therapeutic considerations. Ann. Intern. Med. 1978; 89:660-676. [PubMed]

(9). E. Casta ner, A. Alguersuari, X. Gallardo et al., "When to suspectpulmonaryvasculitis: radiologic and clinical clues," Radiographics,vol. 30, no. 1, pp. 33-53, 2010. 
(10). Choi YH, Im JG, Han BK, Kim JH, Lee KY,Myoung NH. Thoracic manifestation of Churg-Strauss syndrome: radiologic and clinical findings. Chest 2000;117(1):117-124.

(11). L. Ananthakrishnan, N. Sharma, and J. P. Kanne, "Wegener's granulomatosis in the chest: high-resolution CT findings, "American Journal of Roentgenology, vol. 192, no. 3, pp. 676-682, 2009.

(12) - E. Diot, C. Lavigne, L. Renjard, et al., "Wegener's diseasemimicking acute infectious pleurisy," Revue de Pneumologie Clinique, vol. 56, no. 4, pp. 265-268, 2000.

(13) R. Krenke, J. Nosilowsky, P. Korczynski, K. Gorska, T. Przybylowsky, R. Chazan, and R.W.Light, "Incidence and aetiology of eosinophilic pleural effusion," European Respiratory Journal, vol. 34, no. 5, pp.11111117, 2009

\begin{tabular}{|c|c|}
\hline \multicolumn{2}{|c|}{ Access this Article in Online } \\
\hline \multirow{2}{*}{ 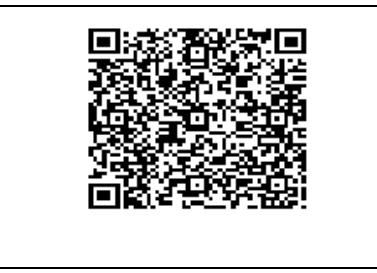 } & $\begin{array}{l}\text { Website: } \\
\text { www.ijcrims.com }\end{array}$ \\
\hline & $\begin{array}{l}\text { Subject: } \\
\text { Medical Sciences }\end{array}$ \\
\hline Quick Response Code & \\
\hline
\end{tabular}

How to cite this article:

Gurpreet Singh, Rajwinder Kaur, NC Kajal, Bakshish Singh, G L Avasthi, N.S. Neki. (2017). ANCA Associated vasculitis presenting as bilateral pleural effusion: A rare case report. Int. J. Curr. Res. Med. Sci. 3(10): 107-111.

DOI: http://dx.doi.org/10.22192/ijcrms.2017.03.10.015 